\title{
Optimal surgical methods to treat intertrochanteric fracture: a Bayesian network meta-analysis based on 36 randomized controlled trials
}

Yan-xiao Cheng and Xia Sheng*

\begin{abstract}
Background: There are several surgical methods to treat intertrochanteric fracture: dynamic hip screw (DHS), compression hip screw (CHS), percutaneous compression plate (PCCP), Medoff sliding plate, less invasive stabilization system (LISS), Gamma nail, proximal femoral nail (PFN), and proximal femoral nail anti-rotating (PFNA). We therefore conducted a network meta-analysis to compare eight surgical interventions, including DHS, CHS, PCCP, Medoff sliding plate, LISS, Gamma nail, PFN, and PFNA, to provide the optimal surgical intervention for intertrochanteric fracture.

Methods: An electronic search of 4 databases (PubMed, Embase, Cochrane library, and Web of Science) from inception to July 2020. Two or more of the eight surgical interventions, including the DHS, CHS, PCCP, Medoff sliding plate, LISS, Gamma nail, PFN, and PFNA, for intertrochanteric fracture were included. The methodological quality of the included studies was assessed using the Cochrane Collaboration risk of bias (ROB) tool. Network meta-analysis was conducted by using R-3.5.1 software with the help of package "gemtc". The odd ratios (ORs) with 95\% credibility interval (Crl) were used to assess complications and standard mean difference (SMD) with 95\% Crl to calculate the continuous outcomes (operative time, intraoperative blood loss, and Harris hip score). Surfaces under the cumulative ranking curves (SUCRA) were used to rank the intervention.

Results: A total of 36 RCTs were included in this study. The results of this network meta-analysis showed that, compared with the CHS and DHS group, PFNA exhibited a beneficial role in reducing the blood loss (SMD, 152.50; 95\% Crl, 72.93 to 232.45; and SMD, 184.40; 95\% Crl, 132.99 to 235.90, respectively). PFNA achieved the lowest value for the surface under the cumulative ranking curve (SUCRA) for the blood loss (SURCA $=0.072$ ) and highest of Harris hip score (SURCA = 0.912). PCCP may have the lowest probability of the operative time (SURCA $=0.095)$. There were no significant differences among the eight surgical procedures in complications.

Conclusion: PFNA technique is the optimal treatment method for intertrochanteric fracture. Larger, longitudinal RCTs addressing current limitations, including sources of bias, inconsistency, and imprecision, are needed to provide more robust and consistent evidence.
\end{abstract}

Keywords: Intertrochanteric fracture, Surgical interventions, Harris hip scores, Network meta-analysis

\footnotetext{
* Correspondence: shengxia0155@sina.com

Department of Orthopedics, Jingjiang People's Hospital, No.28, Zhongzhou

Road, Jingjiang, Taizhou City 214500, Jiangsu Province, China
}

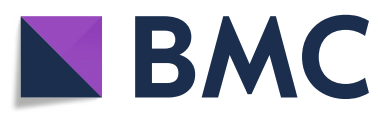

(c) The Author(s). 2020 Open Access This article is licensed under a Creative Commons Attribution 4.0 International License, which permits use, sharing, adaptation, distribution and reproduction in any medium or format, as long as you give appropriate credit to the original author(s) and the source, provide a link to the Creative Commons licence, and indicate if changes were made. The images or other third party material in this article are included in the article's Creative Commons licence, unless indicated otherwise in a credit line to the material. If material is not included in the article's Creative Commons licence and your intended use is not permitted by statutory regulation or exceeds the permitted use, you will need to obtain permission directly from the copyright holder. To view a copy of this licence, visit http://creativecommons.org/licenses/by/4.0/. The Creative Commons Public Domain Dedication waiver (http://creativecommons.org/publicdomain/zero/1.0/) applies to the data made available in this article, unless otherwise stated in a credit line to the data. 


\section{Background}

Intertrochanteric fractures are common injuries in elderly, with estimated prevalence of intertrochanteric fractures greater than 150,000 cases in the USA annually $[1,2]$. Patients with intertrochanteric fractures always have a history of falls or bone disease, which might be due to a low-energy mechanism including fall from standing [3, 4]. Further, the typical clinical manifestations include pain and difficulty walking. The aging was associated with a greater risk of intertrochanteric fractures, and the mortality rate from intertrochanteric fractures ranged from 12 to $41 \%$ within 6 months [5]. The goal of treatment of patients with intertrochanteric fractures was to reduce the morbidity, mortality, reoperation, and early mobility [6].

Several surgical methods have already been demonstrated to be effective for patients with intertrochanteric fractures, mainly including extramedullary fixation (dynamic hip screw (DHS), compression hip screw (CHS), percutaneous compression plate (PCCP), Medoff sliding plate, and less invasive stabilization system (LISS)) and intramedullary fixation (Gamma nail, proximal femoral nail (PFN), and proximal femoral nail anti-rotating (PFNA)) [7-14]. Generally, intramedullary fixation is a valuable alternative method for patients with intertrochanteric fractures, which could be associated with lower levels of operation time, blood loss, and tissue damage.

The percutaneous compression plate (PCCP) was developed in the late 1990 s by Gotfried for fixation in patients with intertrochanteric fractures [15]. This method could minimize operative trauma using two small percutaneous portals and small-diameter drilling, which could lower additional bone damage in the remaining lateral trochanteric wall. Previous studies illustrated that PFNA was associated with a lower risk of implant-related complications and could provide angular and rotational stability [16]. These characteristics, with early mobilization and weightbearing, were suitable for patients with osteoporotic bone and unstable intertrochanteric fractures. LISS has some advantages in the treatment of complex proximal femoral fractures in a more stable construct with higher pullout resistance [17].

Previous studies have tested different internal fixation techniques for the surgical treatment to provide insight into the option for treating intertrochanteric fractures. However, there is no consensus about the optimal surgical method for intertrochanteric fractures [18, 19]. More important, traditional meta-analyses only compare two treatments, while network meta-analysis allows for the simultaneous comparison of multiple interventions through combination of direct and indirect evidences from RCTs.
Therefore, a Bayesian network meta-analysis was performed to compare eight common surgical methods, including DHS, CHS, PCCP, Medoff sliding plate, LISS, Gamma nail, PFN, and PFNA, to provide the optimum treatment method for intertrochanteric fracture.

\section{Material and methods}

This systematic review was written according to the Preferred Reporting Items for Systematic Reviews and Meta-Analysis (PRISMA) Extension Statement for Meta-analysis. Ethical approval was not required as the work was collected data from published literatures.

\section{Search strategy}

PubMed, Embase, Cochrane library, and Web of Science were searched for potentially relevant studies from the time of the inception to July 2020. The terms used for the literature search were as follows: "percutaneous compression plate" OR "proximal femoral nail anti-rotation" OR "proximal femoral nail" OR "less invasive stabilization system" OR "dynamic hip screw" OR "compression hip screw" OR "Medoff sliding plate" AND "intertrochanteric fractures". In addition, we performed a manual search according to the references of eligible studies to prevent any omissions. Study topic, design, intervention, control, and investigated outcomes were employed to identify any included studies. The literature search and study selection were conducted by two authors independently using a standardized approach. Any inconsistency was resolved by group discussion until a consensus was reached.

\section{Inclusion and exclusion criteria}

Studies were pooled for meta-analysis if they met the following criteria: (1) the study with RCTs; (2) the head to head RCT that compares any of the following two comparisons: DHS, CHS, PCCP, Medoff sliding plate, LISS, Gamma nail, PFN, and PFNA; (3) the study presenting the relevant outcomes, including blood loss, Harris hip score, operation time, and complications; and (4) intertrochanteric fractures were confirmed via X-ray imaging.

\section{Data extraction}

Two reviewers (Yan-xiao Cheng and Xia Sheng) independently extracted data in pre-designed proforma and managed using Microsoft Excel 2010 (Microsoft Corp, Redmond, WA). Any discrepancy was resolved by a consensus meeting between the two reviewers. Following information including first author's name, publication year, study design, sample size, mean age, percentage of 
males, Orthopaedic Trauma Association (OTA) fracture classification, and investigated outcomes (blood loss, Harris hip scores, operation time, and postoperative complications) were extracted.

\section{Quality assessment}

The methodological quality of each randomized controlled trials (RCTs) was assessed according to the Cochrane Collaboration tool for assessing the risk of bias (ROB). A total of seven items were included for assessment: random sequence generation, allocation concealment, blinding of participant and personnel, blinding of outcome assessment, incomplete outcome data, selective outcome reporting, and other bias.

\section{Statistical analysis}

Network meta-analysis was conducted using a Bayesian approach using $\mathrm{R}$ version 3.5.1 ( $\mathrm{R}$ Project for Statistical Computing) through the library gemtc. Node splitting method will be used to evaluate the inconsistency between direct and indirect comparisons. There was no significant inconsistency when 95\% CIs of inconsistency factors include zero or $P$ value > 0.05 for the comparison between direct and indirect effects. Heterogeneity of study results was assessed using $I^{2}$ test, and significant heterogeneity was considered at $I^{2}>50 \%$. The clinical outcome (operation time, intraoperative blood loss, and Harris hip scores) was evaluated by the standard mean difference (SMD) with $95 \%$ credibility interval (CrI). Postoperative complications were expressed as odds ratios (ORs) with 95\% CIs. Comparison-adjusted funnel plots were performed by Stata 14.2 (Stata Corp, College Station, TX) to assess publication bias for network metaanalyses.

\section{Result \\ Study characteristics}

A total of 3524 studies were identified from the electronic search, and additional 15 records were identified through other sources. Using Endnote software (Clarivate Analytics), a total of 1182 duplicated articles were excluded. A total of 2223 obviously irrelevant studies were excluded after reading the title and the abstract; another 83 studies were excluded due to various reasons after reading the full text. Finally, a total of 36 studies were included in this meta-analysis [20-52]. A flow chart diagram of the search strategy and study selection is provided in Fig. 1, and the general characteristics of the included studies are presented in Table 1.

Six comparisons evaluated the effect of Gamma nail and CHS, 10 comparisons evaluated the effect of Gamma nail and DHS, 5 comparisons evaluated the effect of PFNA and DHS, 2 comparisons evaluated the PCCP and CHS, 2 comparisons evaluated the effect of PCCP and CHS, 2 comparisons evaluated the Gamma nail and PFNA, 1 comparison evaluated the Gamma nail and PFN, 1 study evaluated LISS and PFNA, 1 study evaluated DHS and Medoff sliding plate, 1 study evaluated PCCP and PFNA, and 1 study evaluated PCCP and DHS. Follow-up duration ranged from 3 to 19 months (mean follow-up duration $=10.06$ months). Figure 2 graphically represents the network of eligible comparisons for the blood loss, Harris hip score, operative time, and complications of the network meta-analysis.

\section{Methodological quality}

All included studies in the meta-analysis were judged to be at high/unclear risk of bias. High/unclear risk of bias was assessed because all included studies had not described adequate blind method and sample calculation. Random sequence generation was adequate in only 12 studies. The details regarding the risk of bias for each included study are shown in Fig. 3.

\section{Results from network meta-analysis Blood loss}

A total of 35 studies reported the intraoperative blood loss. Pooled results revealed that Gamma nail could significantly decrease blood loss than CHS (SMD, 76.16; 95\% CrI, 17.78 to 134.71, Table 2) and DHS (SMD, 108.05; 95\% CrI, 67.16 to 149.07 , Table 2). Moreover, Gamma nail could decrease blood loss than LISS (SMD, - 197.87; 95\% CrI, - 349.78 to - 45.44, Table 2) and Medoff sliding plate (SMD, - 150.74; 95\% CrI, - 232.93 to -68.17 , Table 2).

PCCP could significantly decrease the blood loss than CHS (SMD, 111.14; 95\% CrI, 32.73 to 189.61, Table 2), DHS (SMD, 143.12; 95\% CrI, 88.36 to 197.79, Table 2), LISS (SMD, 232.87; 95\% CrI, 75.76 to 389.37), and Medoff sliding plate (SMD, 185.81; 95\% CrI, 86.09 to 285.40 , Table 2).

PFN could also decrease blood loss than CHS (SMD, 192.01; 95\% CrI, 39.72 to 344.08, Table 2), DHS (SMD, 224.03; 95\% CrI, 76.76 to 370.03 , Table 2), LISS (SMD, 313.46; 95\% CrI, 106.62 to 520.79, Table 2), and Medoff sliding plate (SMD, 266.76; 95\% CrI, 103.64 to 428.84 , Table 2).

The results of this network meta-analysis showed that, compared with the CHS and DHS group, PFNA exhibited a beneficial role in reducing the blood loss (SMD, 152.50; 95\% CrI, 72.93 to 232.45; and SMD, 184.40; $95 \%$ CrI, 132.99 to 235.90, respectively, Table 2). Compared with Gamma nail, PFNA was associated with a reduction of the blood loss (SMD, 76.32; 95\% CrI, 18.32 to 134.70, Table 2). 


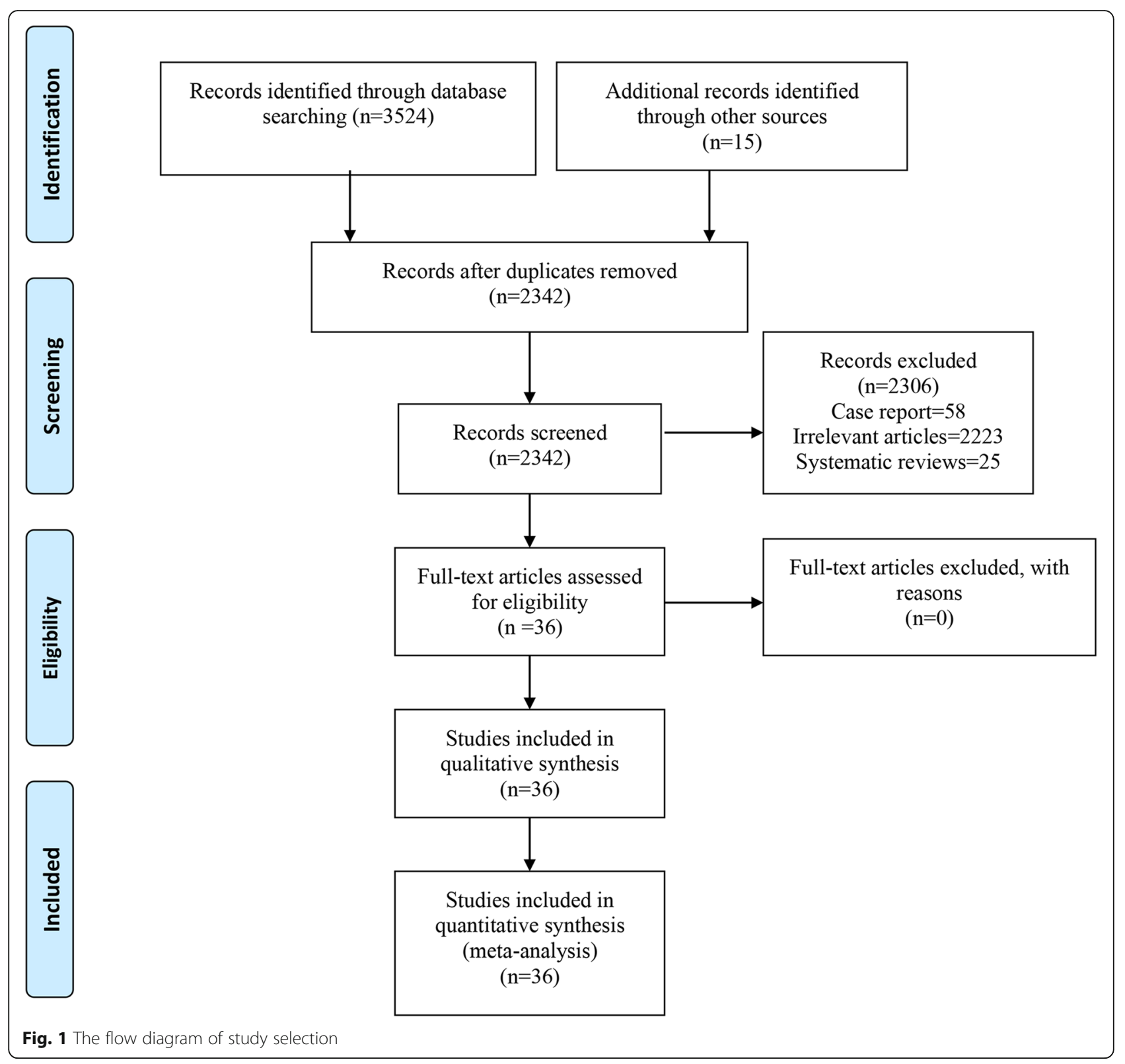

\section{Harris hip score}

Thirty studies were available to assess the effect of eight treatment methods on postoperative Harris hip score. We observed that CHS has a higher Harris hip score than PCCP (SMD = 6.65, $95 \%$ CrI 2.15-11.13, Table 2). Gamma nail could also increase the Harris hip score than PCCP (SMD = 9.46, 95 \% CrI 5.0413.81, Table 2).

The results of this network meta-analysis showed that, compared with the CHS, DHS, Medoff sliding plate, and PCCP group, PFNA exhibited a beneficial role in increasing the Harris hip score (SMD, - 5.88;
95\% CrI, - 10.70, - 1.05; SMD, - 5.72; 95\% CrI, - 9.37 to - 2.06; SMD, - 8.28; $95 \% \mathrm{CrI},-14.29$ to - 2.34; SMD, -12.53 ; $95 \%$ CrI, -17.28 to -7.72 , respectively, Table 2).

\section{Operative time}

Twenty-eight studies reported different treatment methods for the operative time. We found that PCCP could significantly decrease the operative time than CHS (SMD, 36.94, 95\% CrI, 6.62 to 67.30, Table 2), DHS (SMD, 30.68; 95\% CrI, 8.18 to 53.29, Table 2), LISS (SMD, 88.49; 95\% CrI, 22.88 to 154.23 , Table 2), and 
Table 1 General characteristic of the included studies. NA not available, RCT randomized controlled trial, DHS dynamic hip screw, CHS compression hip screw, PCCP percutaneous compression plate, Medoff sliding plate, LISS less invasive stabilization system, PFN proximal femoral nail, PFNA proximal femoral nail anti-rotating

\begin{tabular}{|c|c|c|c|c|c|c|c|c|}
\hline Authors & Intervention & Comparator & $\begin{array}{l}\text { Follow-up } \\
\text { (months) }\end{array}$ & $\begin{array}{l}\text { Type of } \\
\text { fracture }\end{array}$ & $\begin{array}{l}\text { Age } \\
\text { (mean, year) }\end{array}$ & Study & $\begin{array}{l}\text { BMI } \\
\left(\mathrm{kg} / \mathrm{m}^{2}\right)\end{array}$ & Outcomes \\
\hline Leung et al. [20] & Gamma nail & $\mathrm{CHS}$ & 7.2 & $31-\mathrm{A} 1-\mathrm{A} 3$ & 83.35 & $\mathrm{RCT}$ & NA & $1,2,3,4$ \\
\hline Goldhagen et al. [21] & Gamma nail & DHS & 6 & $31-\mathrm{A} 1-\mathrm{A} 3$ & 80.6 & $\mathrm{RCT}$ & NA & $1,2,3,4$ \\
\hline Butt et al. [22] & Gamma nail & DHS & 6 & $31-\mathrm{A} 2-\mathrm{A} 3$ & 79 & $\mathrm{RCT}$ & NA & $1,2,3,4$ \\
\hline O'Brien et al. [23] & Gamma nail & DHS & 13 & $31-A 1-A 2$ & 81.2 & $\mathrm{RCT}$ & NA & $1,2,3,4$ \\
\hline Hoffman and Lynskey [24] & Gamma nail & DHS & 12 & $31-\mathrm{A} 1-\mathrm{A} 3$ & 62.25 & $\mathrm{RCT}$ & NA & $1,3,4$ \\
\hline Kukla et al. [25] & Gamma nail & DHS & 6 & $31-A 1-A 3$ & 81.9 & $\mathrm{RCT}$ & NA & $1,2,3,4$ \\
\hline Ahrengart et al. [26] & Gamma nail & $\mathrm{CHS}$ & 6 & $31-\mathrm{A} 1-\mathrm{A} 3$ & 79.6 & $\mathrm{RCT}$ & NA & $1,2,3,4$ \\
\hline Kosygan et al. [27] & PCCP & $\mathrm{CHS}$ & 19 & $31-\mathrm{A} 1-\mathrm{A} 3$ & 72.95 & $\mathrm{RCT}$ & NA & $1,2,3,4$ \\
\hline Utrilla et al. [28] & Gamma nail & $\mathrm{CHS}$ & 12 & $31-\mathrm{A} 1-\mathrm{A} 3$ & 80.2 & $\mathrm{RCT}$ & NA & $1,2,3,4$ \\
\hline Ekström et al. [29] & Gamma nail & Medoff sliding plate & 6 & $31-A 2$ & 83.2 & $\mathrm{RCT}$ & NA & $1,2,3,4$ \\
\hline Peyser et al. [30] & PCCP & $\mathrm{CHS}$ & 12 & $31-A 2$ & 80.85 & $\mathrm{RCT}$ & NA & $1,2,3,4$ \\
\hline Romero et al. [31] & DHS & PCCP & 12 & $31-\mathrm{A} 1-\mathrm{A} 3$ & 82.9 & $\mathrm{RCT}$ & NA & $1,2,3,4$ \\
\hline Zou et al. [32] & DHS & PFNA & 12 & $31-\mathrm{A} 1-\mathrm{A} 3$ & 82.5 & $\mathrm{RCT}$ & NA & $1,2,4$ \\
\hline Xu et al. [33] & DHS & PFNA & 12 & $31-\mathrm{A} 1-\mathrm{A} 3$ & 62.25 & $\mathrm{RCT}$ & NA & $1,2,3,4$ \\
\hline Yaozeng et al. [34] & Gamma nail & PFNA & 6 & $31-\mathrm{A} 1-\mathrm{A} 3$ & NS & $\mathrm{RCT}$ & NA & $1,3,4$ \\
\hline Yang et al. [35] & PCCP & DHS & 15 & $31-A 1-A 3$ & 71.2 & $\mathrm{RCT}$ & NA & $1,2,3,4$ \\
\hline Guo et al. [36] & PCCP & PFNA & 12 & $31-A 1-A 2$ & 83.55 & $\mathrm{RCT}$ & NA & $1,2,3,4$ \\
\hline Sharma et al. [37] & PFNA & DHS & 6 & $31-\mathrm{A} 1-\mathrm{A} 3$ & 81 & $\mathrm{RCT}$ & NA & $1,2,3,4$ \\
\hline Singh et al. [38] & PFNA & DHS & 5 & $31-\mathrm{A} 1-\mathrm{A} 3$ & 83.3 & $\mathrm{RCT}$ & NA & $1,2,3,4$ \\
\hline Adeel et al. [39] & PFNA & DHS & 12 & $31-A 1-A 3$ & 82.5 & $\mathrm{RCT}$ & NA & $1,2,3,4$ \\
\hline Brandt et al. [40] & PCCP & DHS & 3 & $31-\mathrm{A} 1-\mathrm{A} 3$ & 71.4 & $\mathrm{RCT}$ & NA & $1,2,3,4$ \\
\hline Bridle et al. [41] & Gamma nail & $\mathrm{DHS}$ & 6 & $31-A 1-A 3$ & NS & $\mathrm{RCT}$ & NA & $1,2,3,4$ \\
\hline Janzing et al. [42] & PCCP & DHS & 12 & $31-\mathrm{A} 1-\mathrm{A} 3$ & 76.2 & $\mathrm{RCT}$ & NA & $1,2,3,4$ \\
\hline Kosygan et al. [27] & PCCP & DHS & 19 & $31-\mathrm{A} 1-\mathrm{A} 3$ & 83 & $\mathrm{RCT}$ & 23.2 & $1,2,3,4$ \\
\hline Madsen et al. [43] & Gamma nail & DHS & 6 & $31-A 1-A 3$ & 82.9 & $\mathrm{RCT}$ & NA & $1,2,3,4$ \\
\hline McCormack et al. [44] & DHS & Medoff sliding plate & 6 & $31-\mathrm{A} 1-\mathrm{A} 3$ & 81 & $\mathrm{RCT}$ & NA & $1,2,3$ \\
\hline Miedel et al. [45] & Gamma nail & Medoff sliding plate & 12 & $31-\mathrm{A} 1-\mathrm{A} 3$ & 68.9 & $\mathrm{RCT}$ & NA & $1,2,3,4$ \\
\hline O'Brien et al. [23] & Gamma nail & DHS & 13 & $31-A 1-A 3$ & 70.4 & $\mathrm{RCT}$ & NA & $1,2,3,4$ \\
\hline Pajarinen et al. [46] & DHS & Gamma nail & 4 & $31-\mathrm{A} 1-\mathrm{A} 2$ & 80.2 & $\mathrm{RCT}$ & 21.8 & $1,2,3,4$ \\
\hline Park et al. [47] & Gamma nail & $\mathrm{CHS}$ & 12 & $31-A 1-A 3$ & 76.2 & $\mathrm{RCT}$ & NA & $1,2,3,4$ \\
\hline Parker et al. [48] & Gamma nail & $\mathrm{CHS}$ & 12 & $31-\mathrm{A} 1-\mathrm{A} 2$ & 72.9 & $\mathrm{RCT}$ & NA & $1,2,3,4$ \\
\hline Radford et al. [49] & DHS & Gamma nail & 12 & $31-\mathrm{A} 1-\mathrm{A} 3$ & NS & $\mathrm{RCT}$ & NA & $1,2,3,4$ \\
\hline Schipper et al. [50] & Gamma nail & PFN & 12 & 31-A1-A3 & NS & $\mathrm{RCT}$ & NA & $1,3,4$ \\
\hline Utrilla et al. [28] & Gamma nail & $\mathrm{CHS}$ & 12 & $31-A 2$ & NS & $\mathrm{RCT}$ & NA & $1,2,3,4$ \\
\hline Vaquero et al. [51] & PFNA & Gamma nail & 12 & $31-\mathrm{A} 1-\mathrm{A} 3$ & 72.85 & $\mathrm{RCT}$ & NA & $1,2,3,4$ \\
\hline Zhou et al. [52] & LISS & PFNA & 12 & 31-A1-A3 & 75.7 & $\mathrm{RCT}$ & NA & $1,2,3,4$ \\
\hline
\end{tabular}



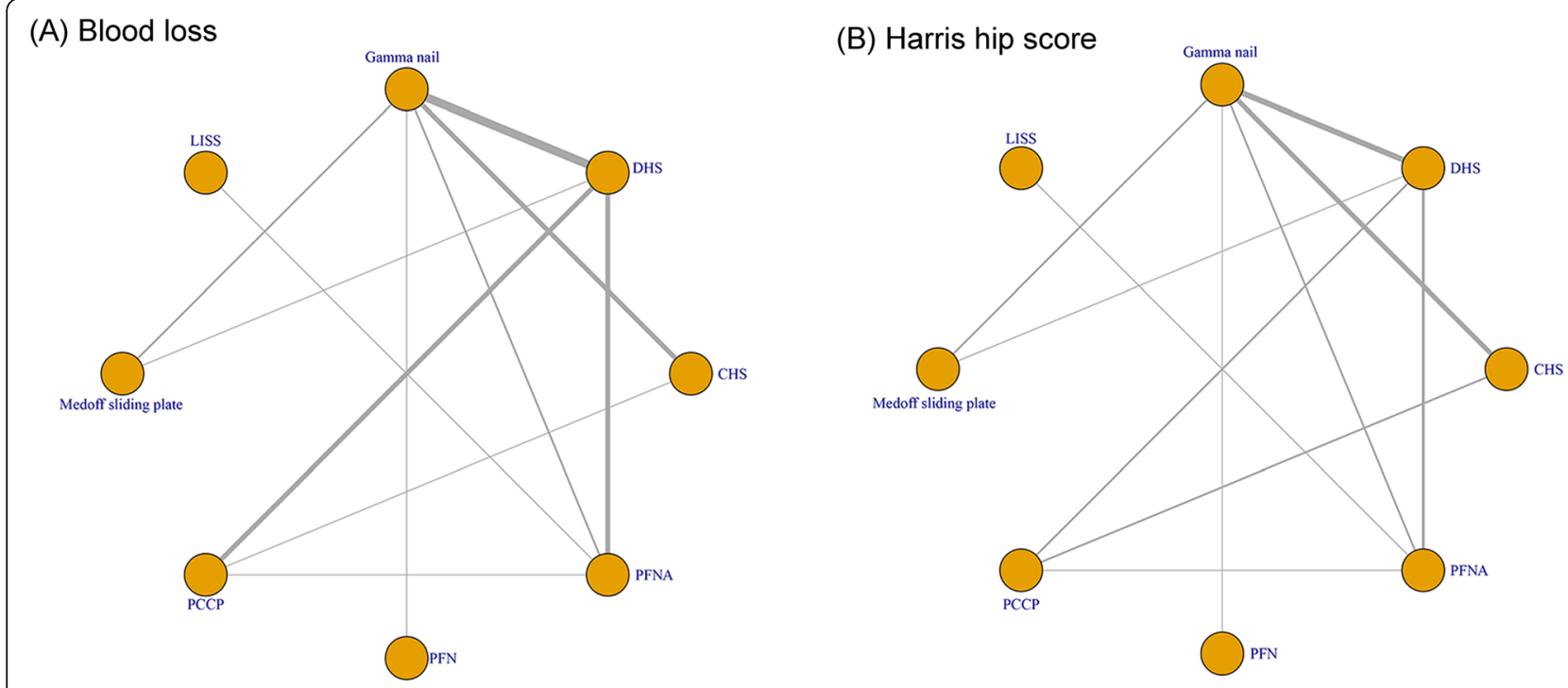

(C) Operative time
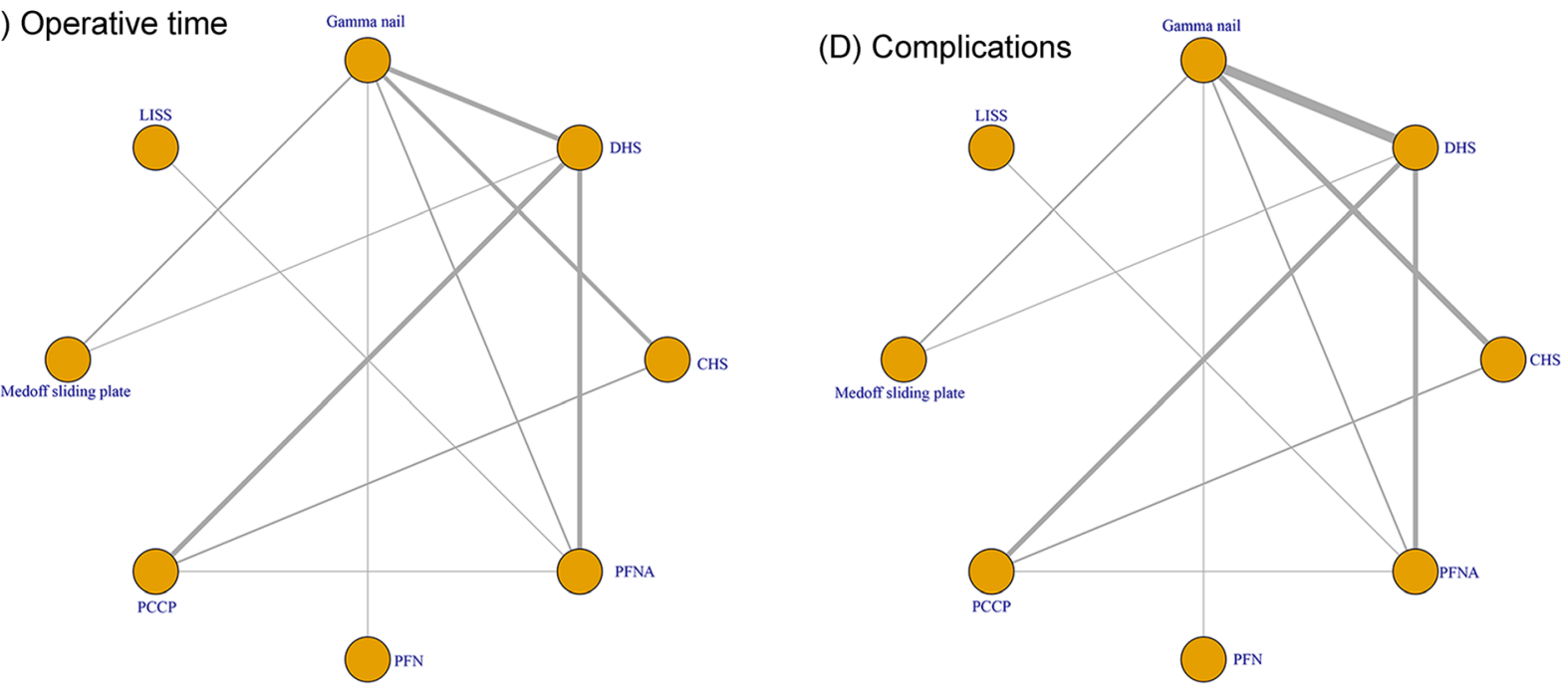

Fig. 2 Evidence network of eligible comparisons for network meta-analysis. Numbers by the lines indicate the cumulative number of enrolled studies for each direct comparison

Medoff sliding plate (SMD, 53.29; 95\% CrI,12.48 to 95.58, Table 2). Moreover, PCCP could significantly decrease the operative time than that of PFNA group (SMD, - 38.50; 95\% CrI, - 67.14 to - 10.11, Table 2).

\section{Complications}

Thirty-two studies were available to assess the eight surgical treatments for postoperative complications. There was no statistical significance among these groups for complications (Table 2).

\section{Relative ranking of eight treatment methods}

Figure 4a reveals the SUCRA probability of the blood loss for the eight surgical methods. PFNA may have the lowest probability of the blood loss (SURCA = 0.072). In Fig. 4b, we summarized the SUCRA probability of the Harris hip score for the eight treatment methods. PFNA may have the highest probability of the Harris hip score (SURCA $=0.912)$.

Figure $4 \mathrm{c}$ summarizes the SUCRA probability of the eight surgical methods for operative time. PCCP may have the lowest probability of the operative time 
Random sequence generation (selection bias) Allocation concealment (selection bias)

Blinding of participants and personnel (performance bias)

Blinding of outcome assessment (detection bias)

Incomplete outcome data (attrition bias)

Selective reporting (reporting bias)

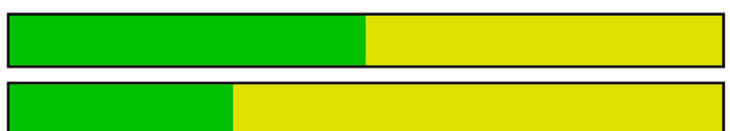

Other bias
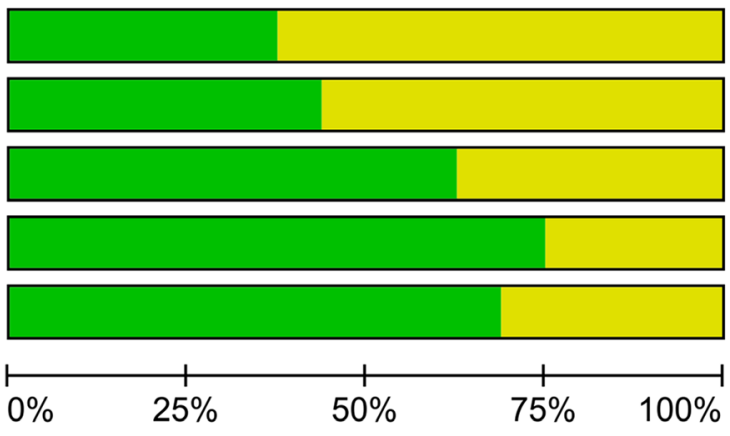

Low risk of bias

Unclear risk of bias

High risk of bias

Fig. 3 Risk of graph of the included studies

(SURCA $=0.095)$. We observed that LISS may have the lowest probability of the incidence of complications (SURCA $=0.280$, Fig. $4 d$ ).

\section{Comparisons between direct and indirect evidences}

The inconsistency between direct and the indirect estimates for each comparison will be further confirmed by node-splitting method. Bayesian $P$ value more than 0.05 indicated that there was no inconsistency of our results. We could easily find that all the $P$ values of node-splitting method were above 0.05 , which indicated the consistency of the direct and indirect evidence for blood loss (Fig. 5). However, significant differences were observed at the comparison between Gamma nail versus CHS and PCCP versus CHS for Harris hip score (Fig. 6). Other comparisons were all above 0.05 , which indicated the consistency of the direct and indirect evidence for Harris hip score. As for operative time, $P$ values of node-splitting method were above 0.05 , except for PFNA versus DHS and PFNA versus Gamma nail $(P<0.05$, Fig. 7$)$. Nevertheless, no significant difference between direct and indirect evidence was observed in complications (Fig. 8).

Table 2 The comparison of eight surgical methods for blood loss, Harris hip score, operative time and complications according to the network meta-analysis using standard mean difference or odds ratios (ORs) and corresponding $95 \%$ credential intervals (Crls). Italics with red colors were with statistically significant

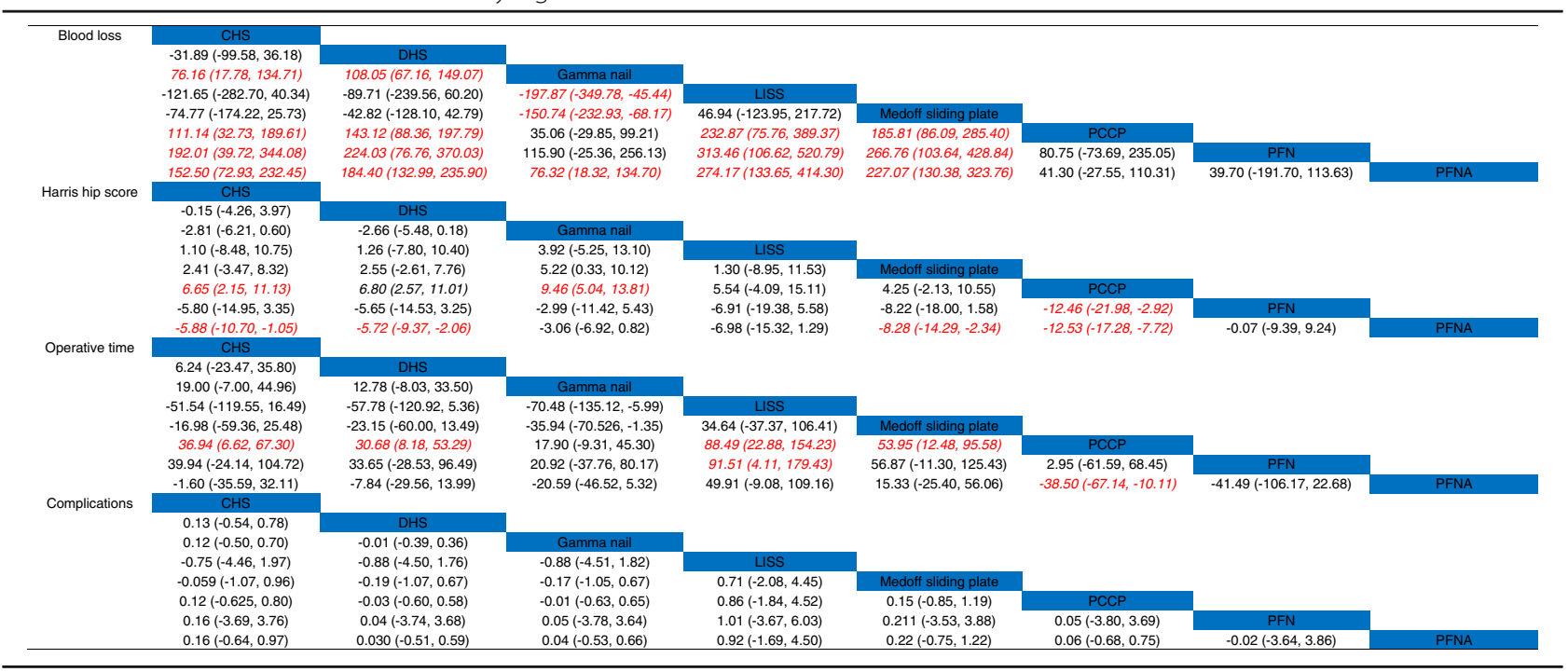




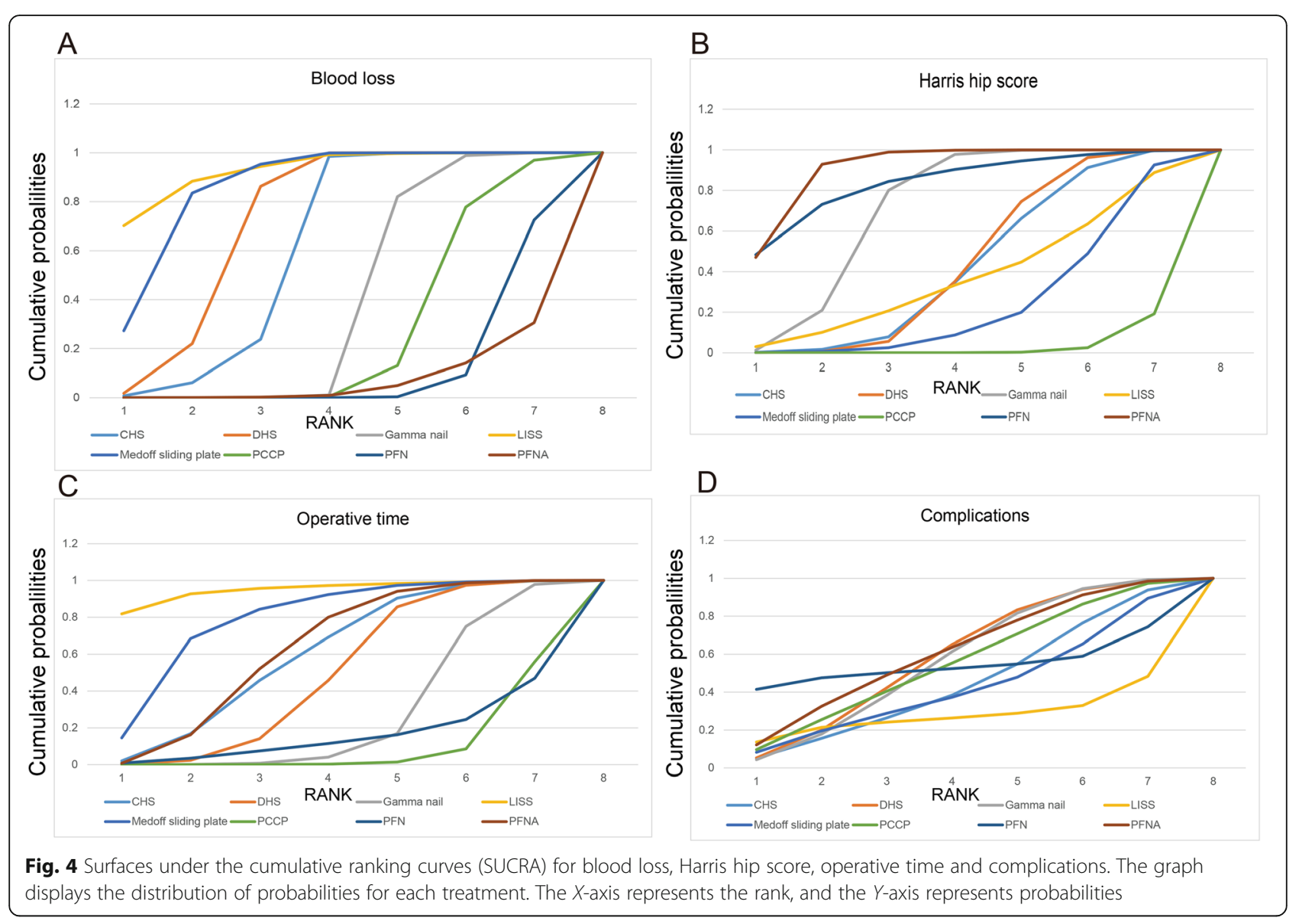

\section{Discussion}

In this network meta-analysis based on 36 RCTs, we systematically reviewed the DHS, CHS, PCCP, MSP, LISS, Gamma nail, PFN, and PFNA for treatment of intertrochanteric fracture. Thirty-six eligible studies were finally involved in this network meta-analysis. PFNA ranked as the most preferable surgical method with less blood loss and higher Harris hip score. As for operative time, PCCP may have the lowest probability of the operative time. However, complications did not differ among these groups. These results may help orthopedic surgeons for the selection of surgical methods for intertrochanteric fracture.

This is the very largest network meta-analysis that compared the efficacy and safety of eight common surgical methods for treatment of intertrochanteric fracture. Previously, Jiang et al. [53] conducted a meta-analysis about efficacy and safety of PFNA and LISS for intertrochanteric fracture; results suggested that PFNA could significantly reduce the hospital stay than LISS. This result is inconsistent with other observations. Arirachakaran et al. [54] suggested that
PCCP was superior than DHS and PFNA in terms of intraoperative outcomes and postoperative complications. However, there were some limitations, including the retrospective study design, mixed PFN and PFNA into a group, and omitted important indicators for hip function. PFNA possesses biological advantage, minimally invasive approach, and easy manipulation. We firstly used blood loss to assess intraoperative advantage between these eight surgical methods. SURCA rank suggested that the blood loss in PFNA ranked the lowest. A major limitation of this outcome is that there is lack of hidden blood loss in these surgical treatments. It needs to be emphasized that hidden blood loss in the operation cannot be overlooked [55, 56]. Therefore, it is urgent to verify the hidden blood loss in these surgical interventions in future studies. Singh et al. [38] conducted a prospective randomized study and found that PFNA requires shorter surgical time and less blood loss than DHS.

For hip functions, we compared Harris hip scores as the main outcome. Regarding the increase of the Harris hip score, PFNA treatment was also ranked as the top 


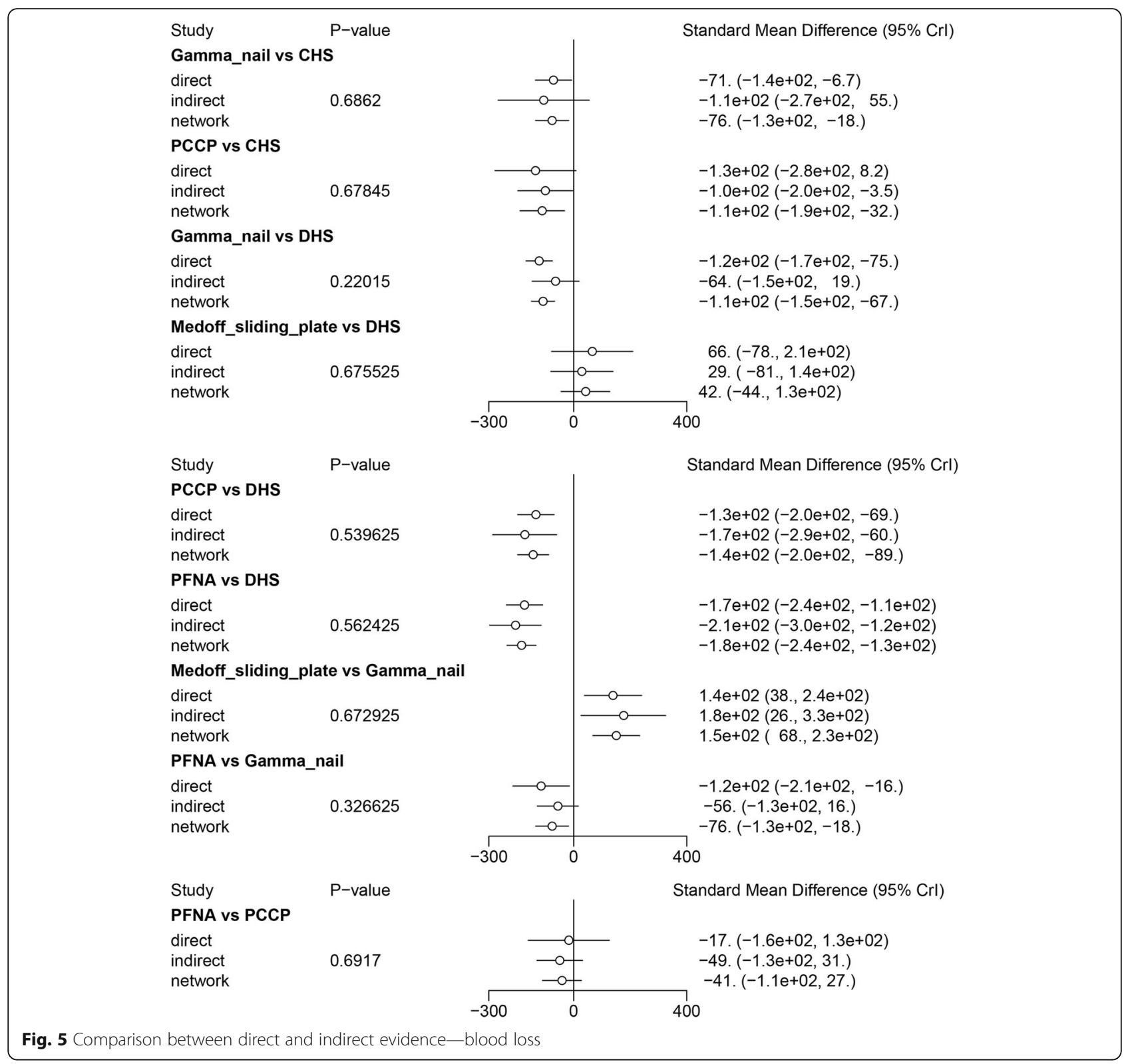

intervention. These results suggested that PFNA could enhance the recovery of the hip function. Xie et al. [57] conducted a controlled study and suggested that PFNA had a better hip recovery than hemi-arthroplasty in intertrochanteric fractures. Ma et al. [58] conducted a meta-analysis about Gamma nail, PFNA, and DHS for intertrochanteric fracture. Results have shown that PFNA was a priority choice with minimal rate of fixation failure and shorter length of hospital stay.

We also compared operative time among the eight surgical methods. Results suggested that PCCP had the lowest probability of operative time than other treatments. However, other studies have drawn the opposite conclusion [19]. Hao et al. [19] suggested that PFNA treatment results in shortest operative time than other surgical treatments. As surgical experience might influence the operative time, thus more validation studies need to be performed. We finally compared complications between these eight treatments; network metaanalysis found that these eight treatments have no statistical significance. Concerning clinical safety, all of these treatments were comparable.

This network meta-analysis had several limitations. The number of included studies was limited and the sample size was small. Further, the quality of this network meta-analysis is limited by the quality of available 


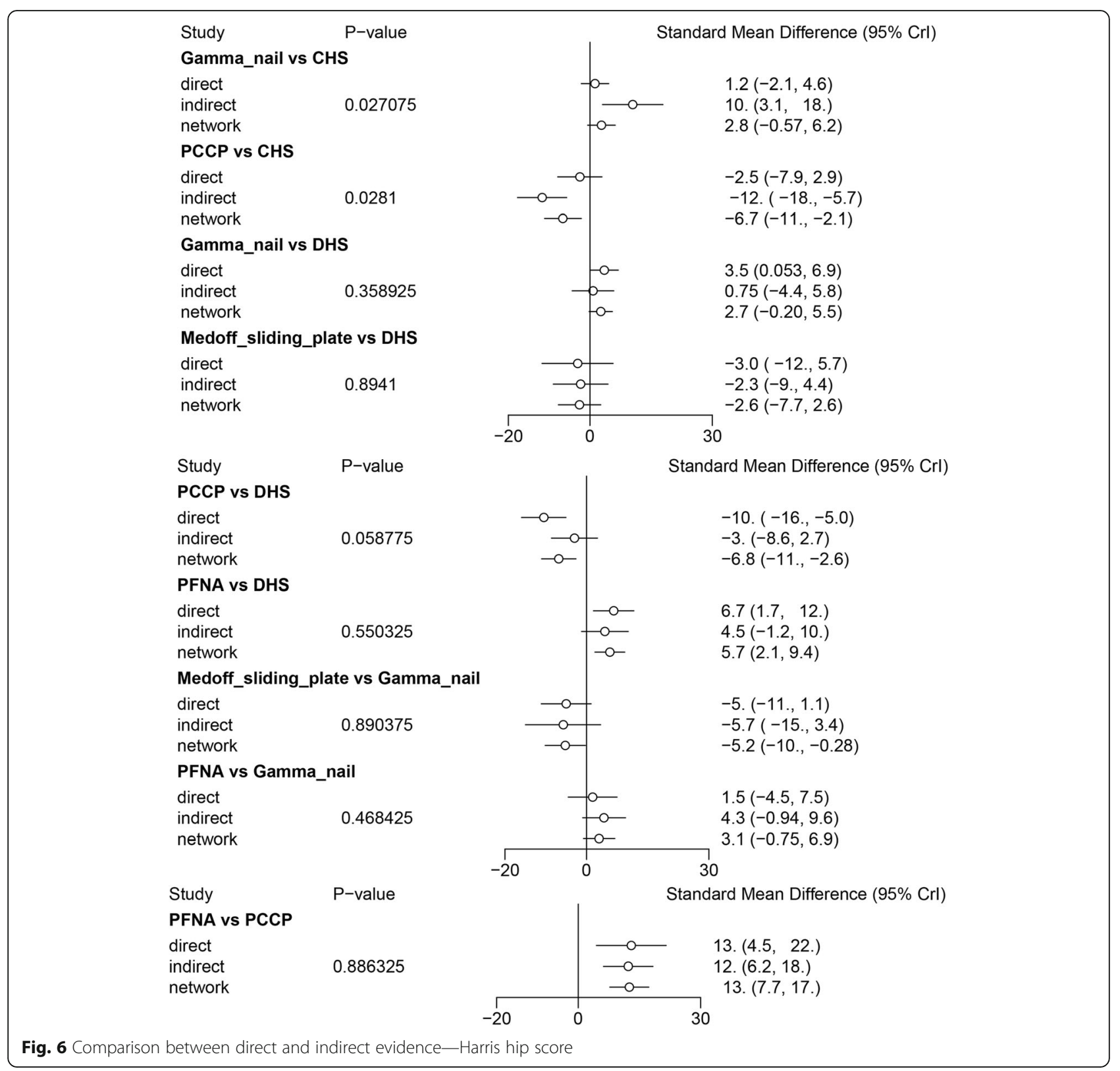




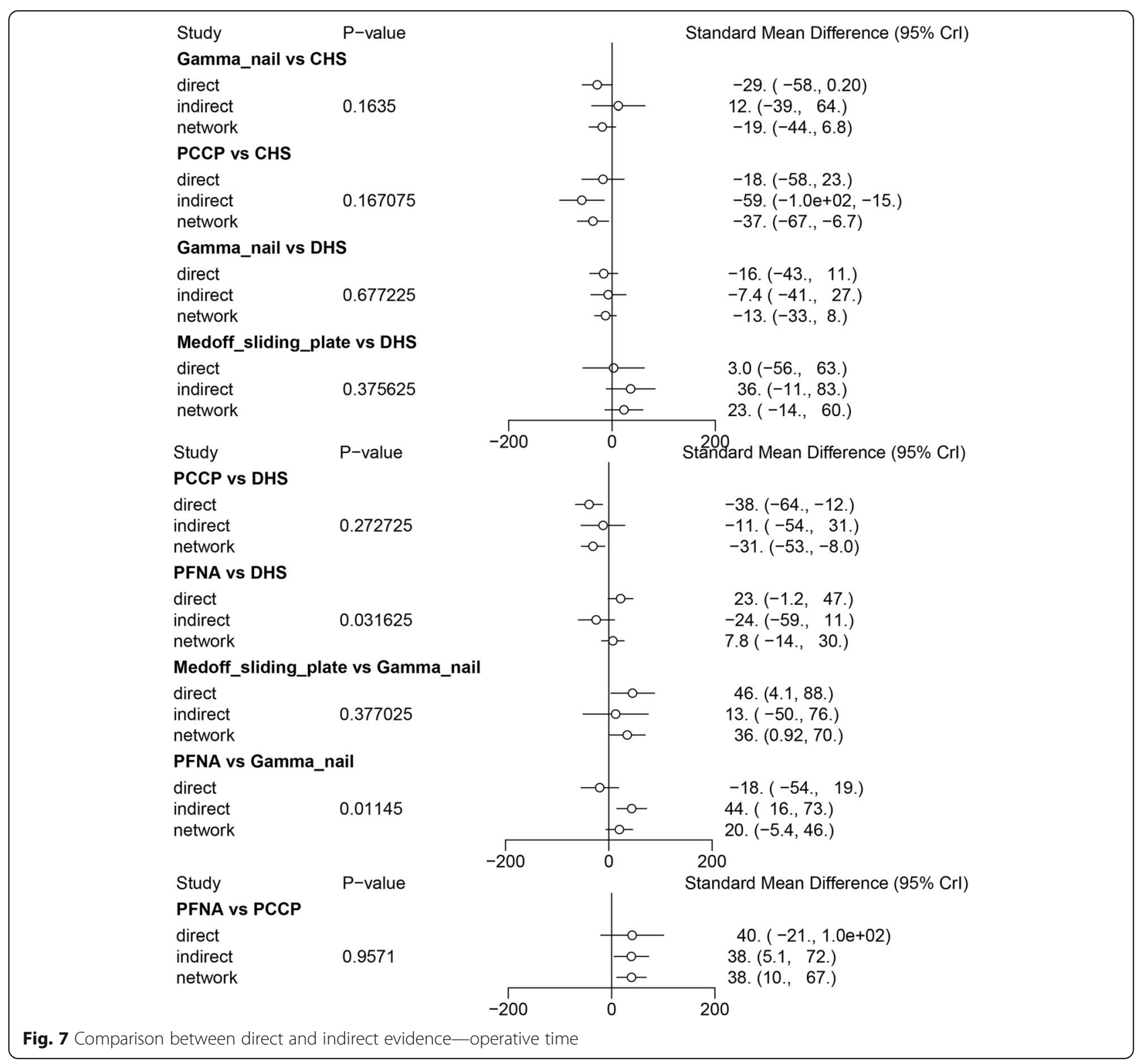




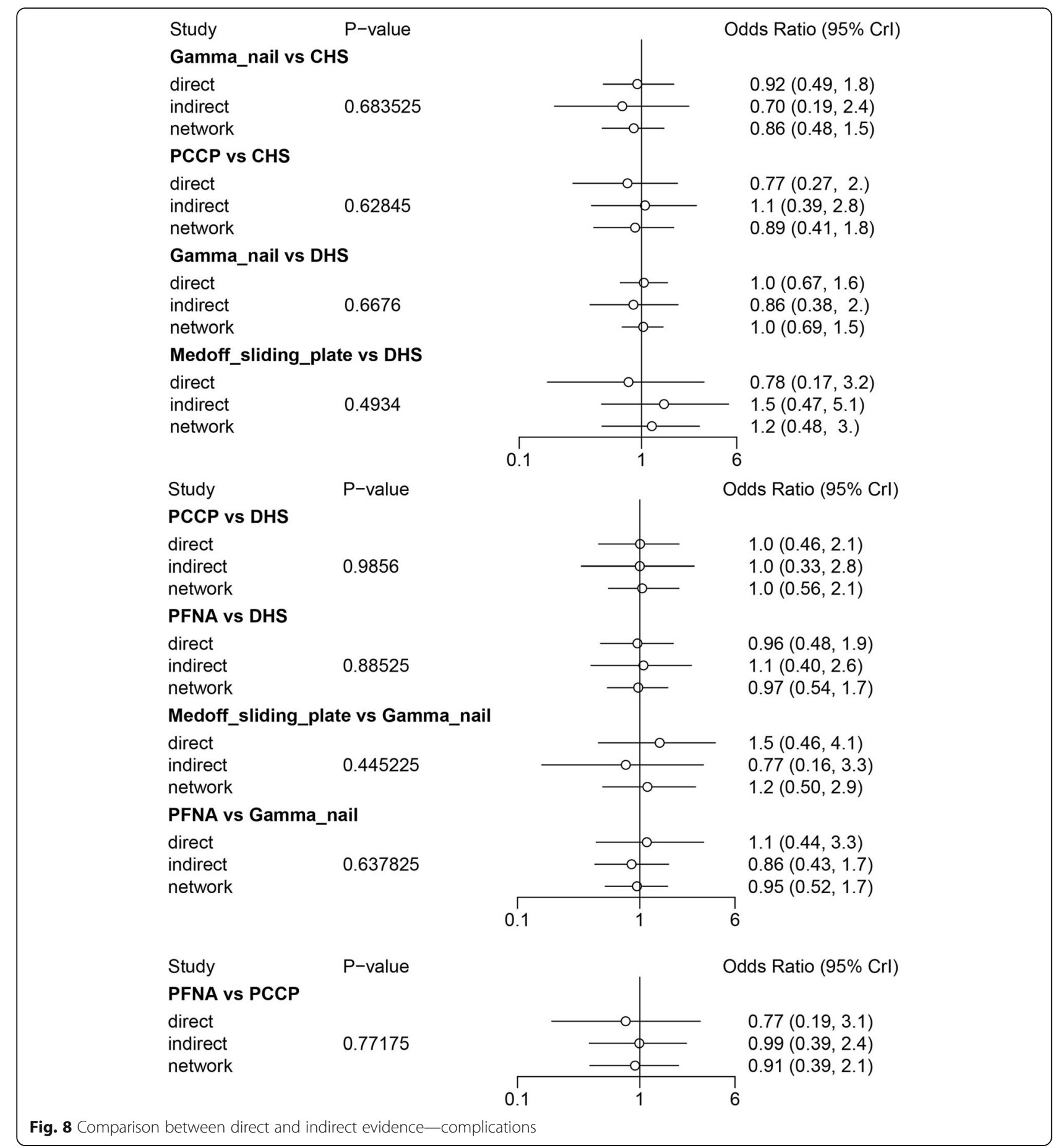

literatures (high/unclear risk of bias). Additionally, the length of load time and postoperative rehabilitation strategies might be further affected by the patients' hip functions. Finally, inconsistency was observed in places (Harris hip score and operative time); further research will be needed to verify it.

\section{Conclusion}

PFNA technique is the optimal treatment method for intertrochanteric fracture. Larger, longitudinal RCTs addressing current limitations, including sources of bias, inconsistency, and imprecision, are needed to provide more robust and consistent evidence. 


\section{Abbreviations}

DHS: Dynamic hip screw; CHS: Compression hip screw; PCCP: Percutaneous compression plate; LISS: Less invasive stabilization system; PFN: Proximal femoral nail; PFNA: Proximal femoral nail anti-rotating; RCTs: Randomized controlled trials; ORs: Odd ratios; Crl: Credibility interval; SMD: Standard mean difference; SUCRA: Surfaces under the cumulative ranking curves; OTA: Orthopaedic Trauma Association; ROB: Risk of bias

\section{Acknowledgements}

Not applicable.

\section{Authors' contributions}

YXC and XS conceived the study design. YXC and XS performed the study, collected the data, and contributed to the study design. YXC and XS prepared the manuscript. YXC and XS edited the manuscript. All authors read and approved the final manuscript.

\section{Funding}

There is no funding for this article.

\section{Availability of data and materials}

We state that the data will not be shared since all the raw data are present in the figures included in the article.

\section{Ethics approval and consent to participate} Not applicable.

\section{Consent for publication}

Not applicable.

\section{Competing interests}

The authors declare that they have no competing interests.

Received: 6 August 2020 Accepted: 1 September 2020

Published online: 10 September 2020

\section{References}

1. Li YH, Yu T, Shao W, Liu Y, Zhu D, Tan L. Distal locked versus unlocked intramedullary nailing for stable intertrochanteric fractures, a systematic review and meta-analysis. BMC Musculoskelet Disord. 2020;21(1):461.

2. Chouhan D, Meena S, Kamboj K, Meena MK, Narang A, Sinha S. Distal locked versus unlocked intramedullary nailing in intertrochanteric fracture; a systematic review and meta-analysis of randomized and non-randomized trials. Bull Emerg Trauma. 2020;8(2):56-61.

3. de Bot R, Veldman HD, Witlox AM, van Rhijn LW, Hiligsmann M. Hip protectors are cost-effective in the prevention of hip fractures in patients with high fracture risk. Osteoporosis Int. 2020:31(7):1217-29.

4. Wada K, Mikami H, Toki S, Amari R, Takai M, Sairyo K. Intra- and inter-rater reliability of a three-dimensional classification system for intertrochanteric fracture using computed tomography. Injury. 2020;1383:30628-8.

5. Sadeghi C, Prentice HA, Okike KM, Paxton EW. Treatment of intertrochanteric femur fractures with long versus short cephalomedullary nails. Permanente J. 2020;24:229.

6. Klaber I, Besa P, Sandoval F, et al. The new AO classification system for intertrochanteric fractures allows better agreement than the original AO classification. An inter- and intra-observer agreement evaluation. Injury. 2020;1383:30628-8.

7. Chang SM, Hou ZY, Hu SJ, Du SC. Intertrochanteric femur fracture treatment in Asia: what we know and what the world can learn. Orthop Clin North America. 2020;51(2):189-205.

8. Niu E, Yang A, Harris AH, Bishop J. Which fixation device is preferred for surgical treatment of intertrochanteric hip fractures in the United States? A survey of orthopaedic surgeons. Clin Orthop Related Res. 2015;473(11): 3647-55.

9. Forte $M L$, Virnig BA, Eberly LE, et al. Provider factors associated with intramedullary nail use for intertrochanteric hip fractures. J Bone Joint Surg Am. 2010:92(5):1105-14.

10. Bovbjerg $P$, Froberg $L$, Schmal $H$. Short versus long intramedullary nails for treatment of intertrochanteric femur fractures ( $A O$ 31-A1 and $A O$ 31-A2): a systematic review. Eur J Orthop Surg Traumat. 2019;29(8):1823-31.
11. Queally JM, Harris E, Handoll HH, Parker MJ. Intramedullary nails for extracapsular hip fractures in adults. Cochrane Database Syst Rev. 2014; 12(9):Cd004961.

12. Kumar P, Rajnish RK, Sharma S, Dhillon MS. Proximal femoral nailing is superior to hemiarthroplasty in AO/OTA A2 and A3 intertrochanteric femur fractures in the elderly: a systematic literature review and meta-analysis. Int Orthop. 2020;44(4):623-33.

13. Mallya S, Kamath SU, Madegowda A, Krishnamurthy SL, Jain MK, Holla R. Comparison of radiological and functional outcome of unstable intertrochanteric femur fractures treated using PFN and PFNA-2 in patients with osteoporosis. Eur J Orthop Surg Traumatol. 2019;29(5):1035-42.

14. Cheng T, Zhang GY, Liu T, Zhang XL. A meta-analysis of percutaneous compression plate versus sliding hip screw for the management of intertrochanteric fractures of the hip. J Trauma Acute Care Surg. 2012;72(5): 1435-43.

15. Shen J, Hu C, Yu S, Huang K, Xie Z. A meta-analysis of percutenous compression plate versus intramedullary nail for treatment of intertrochanteric HIP fractures. Int J Surg (London). 2016;29:151-8.

16. Nherera L, Trueman P, Horner A, Watson T, Johnstone AJ. Comparison of a twin interlocking derotation and compression screw cephalomedullary nail (InterTAN) with a single screw derotation cephalomedullary nail (proximal femoral nail antirotation): a systematic review and meta-analysis for intertrochanteric fractures. J Orthop Surg Res. 2018;13(1):46.

17. Chen Y, Liu S, Lin P, et al. Comparative biomechanical study of reversed less invasive stabilization system and proximal femoral nail antirotation for unstable intertrochanteric fractures. Chinese Med J. 2014;127(23):4124-9.

18. Shen $L$, Zhang $Y$, Shen $Y$, Cui Z. Antirotation proximal femoral nail versus dynamic hip screw for intertrochanteric fractures: a meta-analysis of randomized controlled studies. Orthop Traumatol Surg Res. 2013;99(4):377-83.

19. Hao Z, Wang $X$, Zhang $X$. Comparing surgical interventions for intertrochanteric hip fracture by blood loss and operation time: a network meta-analysis. J Orthop Surg Res. 2018;13(1):157.

20. Leung KS, So WS, Shen WY, Hui PW. Gamma nails and dynamic hip screws for peritrochanteric fractures. A randomised prospective study in elderly patients. J Bone Joint Surg Br. 1992;74(3):345-51.

21. Goldhagen PR, O'Connor DR, Schwarze D, Schwartz E. A prospective comparative study of the compression hip screw and the gamma nail. J Orthop Trauma. 1994;8(5):367-72.

22. Butt MS, Krikler SJ, Nafie S, Ali MS. Comparison of dynamic hip screw and gamma nail: a prospective, randomized, controlled trial. Injury. 1995;26(9): 615-8.

23. O'Brien PJ, Meek RN, Blachut PA, Broekhuyse HM, Sabharwal S. Fixation of intertrochanteric hip fractures: gamma nail versus dynamic hip screw. A randomized, prospective study. Can J Surg. 1995;38(6):516-20.

24. Hoffman CW, Lynskey TG. Intertrochanteric fractures of the femur: a randomized prospective comparison of the Gamma nail and the Ambi hip screw. Aust N Z J Surg. 1996;66(3):151-5.

25. Kukla C, Heinz T, Berger G, Kwasny O, Rosenberger A, Vécsei V. Gamma nail vs. dynamic hip screw in 120 patients over 60 years - a randomized trial. Acta Chirurgica Austriaca. 1997;29(5):290-3.

26. Ahrengart $L$, Törnkvist $H$, Fornander $P$, et al. A randomized study of the compression hip screw and Gamma nail in 426 fractures. Clin Orthop Relat Res. 2002:401:209-22.

27. Kosygan KP, Mohan R, Newman RJ. The Gotfried percutaneous compression plate compared with the conventional classic hip screw for the fixation of intertrochanteric fractures of the hip. J Bone Joint Surg Br. 2002;84(1):19-22.

28. Utrilla AL, Reig JS, Muñoz FM, Tufanisco CB. Trochanteric gamma nail and compression hip screw for trochanteric fractures: a randomized, prospective, comparative study in 210 elderly patients with a new design of the gamma nail. J Orthop Trauma. 2005;19(4):229-33.

29. Ekström W, Karlsson-Thur C, Larsson S, Ragnarsson B, Alberts KA. Functional outcome in treatment of unstable trochanteric and subtrochanteric fractures with the proximal femoral nail and the Medoff sliding plate. J Orthop Trauma. 2007;21(1):18-25.

30. Peyser A, Weil YA, Brocke $L$, et al. A prospective, randomised study comparing the percutaneous compression plate and the compression hip screw for the treatment of intertrochanteric fractures of the hip. J Bone Joint surg Br. 2007:89(9):1210-7.

31. Romero JM, Díaz RA, Oropeza YM. Dynamic hip screw vs. percutaneous compression plate for trochanteric fractures. Acta ortopedica mexicana. 2008:22(2):115-9. 
32. Zou J, Xu Y, Yang H. A comparison of proximal femoral nail antirotation and dynamic hip screw devices in trochanteric fractures. J Int Med Res. 2009; 37(4):1057-64.

33. Xu YZ, Geng DC, Mao HQ, Zhu XS, Yang HL. A comparison of the proximal femoral nail antirotation device and dynamic hip screw in the treatment of unstable pertrochanteric fracture. J Int Med Res. 2010;38(4):1266-75.

34. Yaozeng X, Dechun G, Huilin Y, Guangming Z, Xianbin W. Comparative study of trochanteric fracture treated with the proximal femoral nail antirotation and the third generation of gamma nail. Injury. 2010;41(12):1234-8.

35. Yang E, Qureshi S, Trokhan S, Joseph D. Gotfried percutaneous compression plating compared with sliding hip screw fixation of intertrochanteric hip fractures: a prospective randomized study. J Bone Joint Surg Am. 2011; 93(10):942-7.

36. Guo Q, Shen Y, Zong Z, et al. Percutaneous compression plate versus proximal femoral nail anti-rotation in treating elderly patients with intertrochanteric fractures: a prospective randomized study. J Orthop Sci. 2013;18(6):977-86.

37. Sharma A, Sethi A, Sharma S. Treatment of stable intertrochanteric fractures of the femur with proximal femoral nail versus dynamic hip screw: a comparative study. Rev Brasileira de ortopedia. 2018;53(4):477-81.

38. Singh NK, Sharma V, Trikha V, et al. Is PFNA-II a better implant for stable intertrochanteric fractures in elderly population ? A prospective randomized study. J Clin Orthop Trauma. 2019;10(Suppl 1):S71-s76.

39. Adeel K, Nadeem RD, Akhtar M, Sah RK, Mohy-Ud-Din I. Comparison of proximal femoral nail (PFN) and dynamic hip screw (DHS) for the treatment of $A O$ type $A 2$ and $A 3$ pertrochanteric fractures of femur. JPMA. 2020;70(5): 815-9.

40. Brandt SE, Lefever S, Janzing HM, Broos PL, Pilot P, Houben BJ. Percutaneous compression plating (PCCP) versus the dynamic hip screw for pertrochanteric hip fractures: preliminary results. Injury. 2002;33(5):413-8.

41. Bridle SH, Patel AD, Bircher M, Calvert PT. Fixation of intertrochanteric fractures of the femur. A randomised prospective comparison of the gamma nail and the dynamic hip screw. J Bone Joint Surg Br. 1991;73(2): 330-4.

42. Janzing HM, Houben BJ, Brandt SE, et al. The Gotfried PerCutaneous Compression Plate versus the Dynamic Hip Screw in the treatment of pertrochanteric hip fractures: minimal invasive treatment reduces operative time and postoperative pain. J Trauma. 2002;52(2):293-8.

43. Madsen JE, Naess L, Aune AK, Alho A, Ekeland A, Strømsøe K. Dynamic hip screw with trochanteric stabilizing plate in the treatment of unstable proximal femoral fractures: a comparative study with the Gamma nail and compression hip screw. J Orthop Trauma. 1998;12(4):241-8.

44. McCormack R, Panagiotopolous K, Buckley R, et al. A multicentre, prospective, randomised comparison of the sliding hip screw with the Medoff sliding screw and side plate for unstable intertrochanteric hip fractures. Injury. 2013;44(12):1904-9.

45. Miedel R, Ponzer S, Törnkvist $H$, Söderqvist A, Tidermark J. The standard Gamma nail or the Medoff sliding plate for unstable trochanteric and subtrochanteric fractures. A randomised, controlled trial. J Bone Joint Surg Br. 2005;87(1):68-75.

46. Pajarinen J, Lindahl J, Michelsson O, Savolainen V, Hirvensalo E. Pertrochanteric femoral fractures treated with a dynamic hip screw or a proximal femoral nail. A randomised study comparing post-operative rehabilitation. J Bone Joint Surg Br. 2005;87(1):76-81.

47. Park SR, Kang JS, Kim HS, Lee WH, Kim YH. Treatment of intertrochanteric fracture with the Gamma AP locking nail or by a compression hip screw--a randomised prospective trial. Int Orthop. 1998;22(3):157-60.

48. Parker MJ, Bowers TR, Pryor GA. Sliding hip screw versus the Targon PF nail in the treatment of trochanteric fractures of the hip: a randomised trial of 600 fractures. J Bone Joint Surg Br. 2012;94(3):391-7.

49. Radford PJ, Needoff M, Webb JK. A prospective randomised comparison of the dynamic hip screw and the gamma locking nail. J Bone Joint Surg Br. 1993;75(5):789-93.

50. Schipper IB, Steyerberg EW, Castelein RM, et al. Treatment of unstable trochanteric fractures. Randomised comparison of the gamma nail and the proximal femoral nail. J Bone Joint Surg Br. 2004;86(1):86-94.

51. Vaquero J, Munoz J, Prat S, et al. Proximal Femoral Nail Antirotation versus Gamma3 nail for intramedullary nailing of unstable trochanteric fractures. A randomised comparative study. Injury. 2012;43(Suppl 2):S47-54.

52. Zhou F, Zhang ZS, Yang $H$, et al. Less invasive stabilization system (LISS) versus proximal femoral nail anti-rotation (PFNA) in treating proximal femoral fractures: a prospective randomized study. J Orthop Trauma. 2012; 26(3):155-62.

53. Jiang $X$, Wang $Y$, Ma $X$, et al. Proximal femoral nail antirotation versus reverse less invasive stabilization system-distal femur for treating proximal femoral fractures: a meta-analysis. Medicine. 2016;95(14):e3168.

54. Arirachakaran A, Amphansap T, Thanindratarn P, Piyapittayanun P, Srisawat P, Kongtharvonskul J. Comparative outcome of PFNA, Gamma nails, PCCP, Medoff plate, LISS and dynamic hip screws for fixation in elderly trochanteric fractures: a systematic review and network meta-analysis of randomized controlled trials. Eur J Orthop Surg Traumatol. 2017;27(7):93752.

55. Chen S, Li J, Peng H, Zhou J, Fang H, Zheng $H$. The influence of a halfcourse tourniquet strategy on peri-operative blood loss and early functional recovery in primary total knee arthroplasty. Int Orthop. 2014;38(2):355-9.

56. Zhang S, Xiao C, Yu W, et al. Tranexamic acid safely reduces hidden blood loss in patients undergoing intertrochanteric fracture surgery: a randomized controlled trial. Eur J Trauma Emerg Surg. 2020.

57. Xie Y, Dong Q, Xie Z. Proximal femoral nail anti-rotation (PFNA) and hemiarthroplasty in the treatment of elderly intertrochanteric fractures. Acta Orthop Belgica. 2019;85(2):199-204.

58. Ma KL, Wang $X$, Luan FJ, et al. Proximal femoral nails antirotation, Gamma nails, and dynamic hip screws for fixation of intertrochanteric fractures of femur: A meta-analysis. Orthop Traumatol Surg Res. 2014;100(8):859-66.

\section{Publisher's Note}

Springer Nature remains neutral with regard to jurisdictional claims in published maps and institutional affiliations.
Ready to submit your research? Choose BMC and benefit from:

- fast, convenient online submission

- thorough peer review by experienced researchers in your field

- rapid publication on acceptance

- support for research data, including large and complex data types

- gold Open Access which fosters wider collaboration and increased citations

- maximum visibility for your research: over $100 \mathrm{M}$ website views per year

At $\mathrm{BMC}$, research is always in progress.

Learn more biomedcentral.com/submissions 